einen elektrischen Strom, welcher die Erde in der Richtung des magnetischen Aequators umkreise, entstehe, zerfällt von selbst, sobald man bedenkt, dass es 6 sich in sehr verschiedenen Winkeln schneidende magnetische Aequatoren giebt, da es eben so viele indifferente Linien geben muss als Pole. Die von Morle $\iota$ angegebene Linie scheint aus 5 verschiedenen zusammengesetzt $\mathrm{zu}$ sein. Wenn in der Richtung derselben cin elektrischer Strom die Erde umkreisen sollte, so liesse sich wirklich nicht absehen, wodurch derselbe so oft abgebrochen und unter sehr verschiedener Richtung fortgesetzt werden könnte. Indess lässt sich doch nicht leugnen, dass, sowie die Imponderabilien überhaupt nur Modificationen eines Urstoffes zu sein scheinen, Elektricitat und Magnetismus noch besondere Beziehungen haben duirften. Wir werden auf diese Vermuthung gelcitet, wenn wir das Verhalten der Polargegenden mit dem der heissen Zone vergleichen. Dort finden wir Mangel an Wärme, Anhäufung und Ausstrahlung positiver Elektricität (Nord- und Suidlichter) und die bestimmteste magnetische Relation; in der Nähe des Erdäquators aber grosse Wärme, Anhäufung negativer Elektricität (Gewitter) und magnetischen Indifferentismus. In welcher Beziehung der Magnetismus zur Atmosphäre und zur Witterung stehe, lässt sich jetzt nicht bestimmen und duirfte wohl nur durch genaue Beobachtung und directe Versuche zu ermitteln sein. Einigen Einfluss ubt derselbe wohl aus, denn es ist wenigstens Thatsache, dass die Nord- und Siidlichter stets ein Schwanken der Magnetnadel und Temperaturwechsel in Begleitung haben.

(Beschluss folg t.)

\title{
Ueber zwei neue Doppelsalze der Arsensäure;
}

Dr. H. Baumanu.

Das ähnliche chemische Verhalten, welches die Baryt-, Strontian - und Kalkverbindungen charakterisirt, liess hoffen, dass auch Doppelsalze von Baryt und Strontian, analog 
dem neutralen arsensauren Ammoniakkalke darzustellen seien*). Dieses ist nach demselben Verfahren, nach welchem das zuletzt genannte Doppelsalz erhalten wurde, gelungen.

Man bringt nämlich eine wässerige Auflösung von salpetersaurem Baryt (Strontian), Arsensäure und Ammoniak zusammen. Bei dem richtigen Verhältnisse der angewendeten Stoffe verwandeln sich auch hier nach einiger Zeit, gleichwie es bei der Bildung des erwähnten Kalkdoppelsalzes der Fall ist, die voluminösen Niederschläge der arsensauren Salze durch Aufnahme von Ammoniak in schön krystallisirte feine weisse Nadeln, welche unter dem Mikroskope sich als rhombische Prismen und Tafeln erweisen. Besonders schön ist das Strontiandoppelsalz krystallisirt; die Tafeln sind theils unter sich, theils mit Prismen zu zackigen Gruppirungen vereinigt.

Diese Nadeln verhalten sich chemisch genau wie das entsprechende Kalksalz. Sie verwittern nämlich ebenfalls leicht an der Luft, indem sic Wasser verlieren. Bringt man dieselben mit Wasser in Beruhrung, so nehmen sie dieses wieder auf, was aus der unveränderten Krystallform derselben hervorgeht. In Wasser sind sie unlöslich, dagegen in verdünnter Salpetersäure leicht auflöslich. Beim Erhitzen in der Platinschale entweicht Wasser und Ammoniak, welches letztere durch Salzsäure leicht nachzuweisen ist.

Es verloren 0,123 Grm. des Barytdoppelsalzes durch Erhitzen 0,036 Grm. Diese entsprechen

$$
\begin{aligned}
& 1 \text { At. Ammoniak. . . . 0,0178 Grm. } \\
& 2 \text { "Wasser } \cdots \frac{0,0182 \mathrm{n},}{0,0360 \mathrm{Grm} \text {. }}
\end{aligned}
$$

Die rückständigen $0,087 \mathrm{Grm}$. fester Bestandtheile wurden in Wasser gegeben und mittelst einiger Tropfen Salpetersäure aufgelöst. Aus der Auflösung wurde mittelst Schwefelsäure der Baryt und mittelst essigsauren Bleioxyds die Arsensäure gefällt und aus den erhaltenen Niederschlägen die Gewichtsmengen dieser berechnet. Diese ergaben

$$
\begin{aligned}
& 0,0467 \text { Grm. Arsensŭure und } \\
& 0,0403, \text { Baryt } \\
& \hline 0,0870 \text { Grm., }
\end{aligned}
$$

*) S. dicses Archir Bd. 36. II. 1. p. 36. 
über zwei neue Doppelsalse der Arsensäure. 301

welche Gewichtsmengen einem Atome von jedem der oben genannten Stoffe entsprechen.

Die Zusammensetzung dieses Salzes ist demnach folgende: in $100 \mathrm{Th}$.

$$
\begin{aligned}
& 1 \text { At. } \mathrm{As}^{2} \mathrm{O}^{5}=0,0467 \text { Grm. }-37,94 \\
& 1 \Rightarrow \mathrm{BaO}=0,0403,-33,08 \\
& 1 " \mathrm{H}^{6} \mathrm{~N}^{2}=0,0178 \Rightarrow-14,33 \\
& 2 " \mathrm{H}^{2} \mathrm{O}=0,0182 "-14,65 \\
& \hline 0,1230 \text { Grm. } 100,00 .
\end{aligned}
$$

Auf dieselbe Weise wurden 0,225 Grm. des Strontiandoppelsalzes analysirt. Der Glühverlust betrug 0,090 Grm., also

$$
\begin{aligned}
& 1 \text { At. Ammoniak }=0,04393 \mathrm{Grm} . \\
& 2 " \text { Wasser }=\frac{0,04607,}{0,09000 \mathrm{Grm} .}
\end{aligned}
$$

Für die rückständigen $0,135 \mathrm{Grm}$. fester Bcslandtheile ergaben die Niederschläge durch Rechnung:

$$
\begin{aligned}
& 0,08700 \mathrm{Grm} \text {. Arsensăure } \\
& 0,04800 \quad \text { Strontian } \\
& \hline \mathbf{0 , 1 3 5 0 0 \mathrm { Grm } . ,}
\end{aligned}
$$

welche Gewichtsmengen gleichfalls einem Atom von jedem der beiden Stoffe entsprechen. Folglich ist das Salz zusammengesetzt aus:

$$
\text { in } 100 \mathrm{Th} \text {. }
$$

$$
\begin{aligned}
& 1 \text { At. } \mathrm{As}^{2} \mathbf{0}^{3}=0,08700 \mathrm{Grm} .-38,22 \\
& 1 " \mathrm{Sr}^{2} \mathrm{O}=0,04800,-21,33 \\
& 1 " \quad \mathrm{I}^{6} \mathrm{~N}^{2}=0,04393 \quad,-19,56 \\
& 2 " \mathrm{H}^{2} \mathrm{O}=\frac{0,04607, \quad-20,49}{0,22500 \mathrm{Grm}}
\end{aligned}
$$

Aus dem beim Kalkdoppelsalz angefihiten Grunde crgiebt sich, dass diese Verbindungen die neutralen arsensauren Doppelsalze sind. 